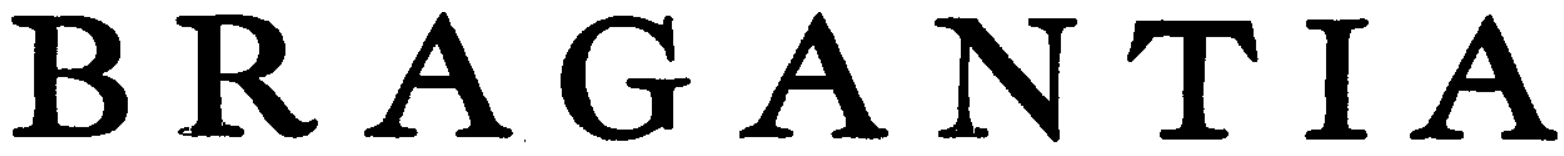

Boletim Técnico da Divisão de Experimentação e Pesquisas INSTITUTO AGRONÔMICO

Vol. 9 Campinas, Maio-Agôsto de $1949 \quad$ N. ${ }^{o 8}$ 5-8

\title{
ENSAIO DE VARIEDADES DE CAFEEIROS II
}

J. E. Teixeira Mendes

Engenheiro agrônomo, Seç̧õo de Café, Instituto Agronômico de Campinas

\section{1-INTRODUÇÃO}

O ensaio de variedades de cafeeiros iniciado na Estação Experimental Central de Campinas, em 1931, teve os seus primeiros resultados publicados em 1939, em Boletim Técnico dêste Instituto - Ensaio de variedades de cafeeiros (1).

Naquela publicação foram examinados os dados de quatro colheitas referentes aos anos de 1935, 1936, 1937 e 1938.

No presente trabalho examinaremos o prosseguimento dêsse ensaio, em seu conjunto, e em relação aos anos de 1939, 1940, 1941, 1942, 1943, 1944, 1945 e 1946.

O plano do ensaio é o mesmo já relatado no referido boletim, entrando em confronto as seguintes variedades:

1 - Café Nacional - Coffea arabica L. var. typica Cramer

2 - Café Amarelo de Botucatu - Coffea arabica L. var. typica Cramer forma xanthocarpa (Caminhoá) Krug

3 - Café Bourbon - Coffea arabica L. var. bourbon (B. Rodr.) Choussy

4 - Café Bourbon Amarelo - Coffea arabica L. var. bourbon (B. Rodr.) Choussy forma xanthocarpa Krug

5 - Cafe Sumatra - Coffea arabica L. var. typica Cramer

6 - Café Maragogipe - Coffea arabica L. var. maragogipe Hort. ex Froehner.

\section{2-ADUBAÇÕES E TRATOS CULTURAIS}

As adubações têm sido feitas anualmente, para que não haja decadência no lote experimental, e em cova por cova, para a maior uniformidade possível nas condições do ensaio. As doses de adubos empregadas foram : 
Ano 1939

grama

.

Palha de cafée........................ 2500

Cloreto de potássio . . . . . . . . . . . . . . . . . . . . 100

Farinha de ossos $\ldots \ldots \ldots \ldots \ldots \ldots \ldots \ldots \ldots \ldots \ldots \ldots \ldots$

Torta de mamona ...................... 500

Sulfato de amônio $\ldots \ldots \ldots \ldots \ldots \ldots \ldots \ldots \ldots \ldots \ldots \ldots$

ANo 1940

Estêrco $\ldots \ldots \ldots \ldots \ldots \ldots \ldots \ldots \ldots \ldots \ldots \ldots \ldots \ldots \ldots \ldots$. 000

Torta de mamona ....................... 1000

Farinha de ossos ......................... 100

Cloreto de potássio $\ldots \ldots \ldots \ldots \ldots \ldots \ldots \ldots \ldots \ldots \ldots \ldots$

ANo 1941

Palha de café $\ldots \ldots \ldots \ldots \ldots \ldots \ldots \ldots \ldots \ldots \ldots \ldots \ldots \ldots \ldots$

Torta de algodäo $\ldots \ldots \ldots \ldots \ldots \ldots \ldots \ldots \ldots \ldots \ldots \ldots \ldots \ldots \ldots 1000$

Cinza de café $\ldots \ldots \ldots \ldots \ldots \ldots \ldots \ldots \ldots \ldots \ldots \ldots \ldots \ldots \ldots \ldots$

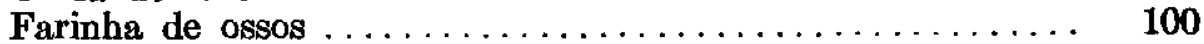

ANo 1942

Estêrco $\ldots \ldots \ldots \ldots \ldots \ldots \ldots \ldots \ldots \ldots \ldots \ldots \ldots \ldots \ldots$

Farelo de algodão $\ldots \ldots \ldots \ldots \ldots \ldots \ldots \ldots \ldots \ldots \ldots \ldots \ldots$

Farinha de ossos . . . . . . . . . . . . . . . . . . . 100

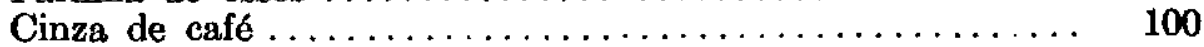

Adubação verde com feijão de porco $\ldots \ldots \ldots \ldots \ldots \ldots \ldots$

ANo 1943

Estêrco $\ldots \ldots \ldots \ldots \ldots \ldots \ldots \ldots \ldots \ldots \ldots \ldots \ldots \ldots \ldots \ldots \ldots \ldots \mathbf{5 0 0}$

Torta de algodão $\ldots \ldots \ldots \ldots \ldots \ldots \ldots \ldots \ldots \ldots \ldots \ldots \ldots 1000$

Farinha de ossos $\ldots \ldots \ldots \ldots \ldots \ldots \ldots \ldots \ldots \ldots \ldots \ldots \ldots \ldots$

Cinza de café $\ldots \ldots \ldots \ldots \ldots \ldots \ldots \ldots \ldots \ldots \ldots \ldots \ldots \ldots \ldots$

Avo 1944

Torta de algodão $\ldots \ldots \ldots \ldots \ldots \ldots \ldots \ldots \ldots \ldots \ldots \ldots 1000$

Farinha de ossos $\ldots \ldots \ldots \ldots \ldots \ldots \ldots \ldots \ldots \ldots \ldots \ldots$

Cinza de cafe $\ldots \ldots \ldots \ldots \ldots \ldots \ldots \ldots \ldots \ldots \ldots \ldots \ldots$

Ano 1945

Estêrco $\ldots \ldots \ldots \ldots \ldots \ldots \ldots \ldots \ldots \ldots \ldots \ldots \ldots \ldots \ldots \ldots \ldots 5000$

Torta de algodão $\ldots \ldots \ldots \ldots \ldots \ldots \ldots \ldots \ldots \ldots \ldots \ldots \ldots \ldots \ldots \ldots 1500$

Fosfato potássico . . . . . . . . . . . . . . 300

Ano 1946

Estêrco $\ldots \ldots \ldots \ldots \ldots \ldots \ldots \ldots \ldots \ldots \ldots \ldots \ldots \ldots \ldots$

Torta de algodão $\ldots \ldots \ldots \ldots \ldots \ldots \ldots \ldots \ldots \ldots \ldots \ldots$

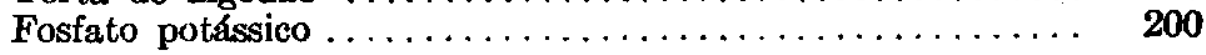

Os tratos culturais têm sido aquêles que se fazem em uma lavoura bem cuidada de café : capinas regulares, desbrotas, ligeira poda, para que a saia (!) não forme um trançado inextricável de ramos. $O$ contrôle à erosão é garantido por um sistema de curvas de nível que vem funcionando a contento.

(1) Conjunto de ramos inferiores do cafeeiro. 


\section{3-COLHEITA E RESULTADOS OBTIDOS ATE 1938}

A colheita tem sido realizada, desde o principio do ensaio, tantas vêzes quantas necessárias para se colhêr café maduro. Normalmente, três repasses nas árvores, por ano, têm sido suficientes para se obter, tanto quanto possível, só café maduro.

A média da produção, por variedade, nos quatro primeiros anos (1935, 1936, 1937 e 1938), foi a seguinte, expressa em café em côco e por fileira de 50 árvores:

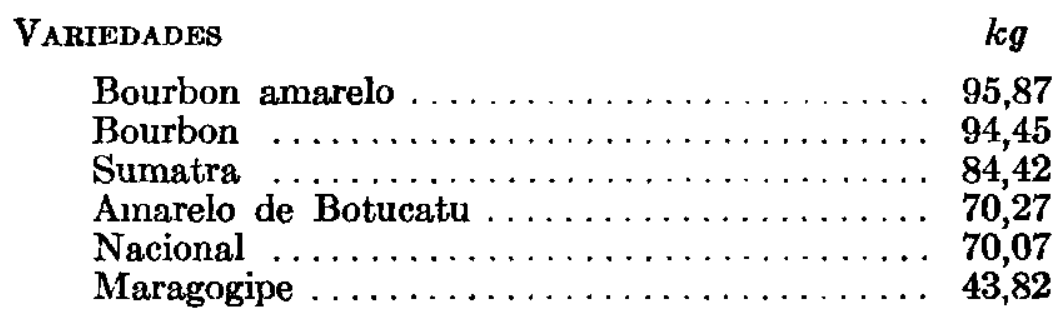

Vejamos, agora, como se processaram as colheitas nos anos seguintes.

\section{4-RESULTADOS OBTIDOS DE 1939 A 1946}

\section{1-COLHEITA DE 1939}

a) Produção total - Este foi um ano que se caraterizou pela queda brusca da produção para tôdas as variedades do ensaio. $O$ quadro 1 dá uma relação da colheita média das cinco repetiçóes de cada uma das variedades.

Quadro 1.-Produções médias das variedades em 1939

\begin{tabular}{|c|c|c|c|}
\hline \multirow[b]{2}{*}{ Variedade ou forma } & \multicolumn{3}{|c|}{ Produção de café } \\
\hline & Cereja & Em côco & Beneficiado \\
\hline & $k g$ & $k g$ & $k g$ \\
\hline 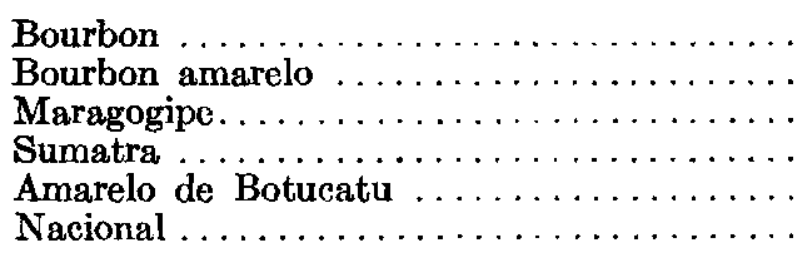 & $\begin{array}{r}233,840 \\
184,360 \\
141,100 \\
109,520 \\
98,060 \\
90,660\end{array}$ & $\begin{array}{r}102,550 \\
80,670 \\
60,700 \\
47,870 \\
46,600 \\
38,870\end{array}$ & $\begin{array}{l}49,180 \\
39,470 \\
33,040 \\
24,330 \\
21,670 \\
19,790\end{array}$ \\
\hline
\end{tabular}

A variedade Bourbon colocou-se, indiscutivelmente, em primeiro lugar; em segundo, vem o Bourbon amarelo. A variedade Maragogipe vem no terceiro pôsto, suplantando as outras três. 
b) Época da maturação dos frutos - A colheita foi feita em quatro épocas. Se examinarmos a percentagem de frutos retirados das árvores em cada uma delas, iremos ter elementos para avaliar como se processou o amadurecimento (quadro 2).

Quadro 2.-Produções e percentagens de café cereja nas diversas colheitas das variedades em 1939

\begin{tabular}{|c|c|c|c|c|c|c|c|}
\hline \multirow{3}{*}{ Variedade ou forma } & \multicolumn{7}{|c|}{ Produções de café cereja } \\
\hline & \multicolumn{4}{|c|}{ Em pêso } & \multicolumn{3}{|c|}{ Em percentagem } \\
\hline & $\begin{array}{l}\text { primeira } \\
\text { colbeita }\end{array}$ & $\begin{array}{l}\text { segunda } \\
\text { colheita }\end{array}$ & $\begin{array}{l}\text { terceira } \\
\text { colheita }\end{array}$ & $\begin{array}{l}\text { quarta } \\
\text { colheita }\end{array}$ & $\begin{array}{l}\text { primeira } \\
\text { colheita }\end{array}$ & $\begin{array}{l}\text { segunda } \\
\text { colheita }\end{array}$ & $\begin{array}{l}\text { terceira } \\
\text { colheita }\end{array}$ \\
\hline & $\mathrm{kg}$ & $k g$ & $k g$ & $\mathrm{~kg}$ & $\%$ & $\%$ & $\%$ \\
\hline $\begin{array}{l}\text { Amarelo de Botucatu } \\
\text { Nacional } \ldots \ldots \ldots \ldots \\
\text { Sumatra } \ldots \ldots \ldots \\
\text { Bourbon } \ldots \ldots \ldots \\
\text { Bourbon amarelo } \ldots \\
\text { Maragogipe . . . . }\end{array}$ & $\begin{array}{l}56,240 \\
43,820 \\
50,360 \\
84,900 \\
61,120 \\
18,440\end{array}$ & $\begin{array}{r}34,660 \\
38,820 \\
46,940 \\
112,580 \\
85,600 \\
76,700\end{array}$ & $\begin{array}{r}2,680 \\
2,820 \\
3,980 \\
11,780 \\
11,460 \\
14,280\end{array}$ & $\begin{array}{r}4,480 \\
5,200 \\
8,240 \\
24,580 \\
26,180 \\
31,680\end{array}$ & $\begin{array}{l}57,35 \\
48,33 \\
45,98 \\
36,30 \\
33,15 \\
13,06\end{array}$ & $\begin{array}{l}35,34 \\
42,81 \\
42,85 \\
48,14 \\
46,43 \\
54,35\end{array}$ & $\begin{array}{r}2,73 \\
3,11 \\
3,63 \\
5,03 \\
6,21 \\
10,12\end{array}$ \\
\hline
\end{tabular}

Verifica-se, de novo, que a variedade Maragogipe é mais tardia que as demais. Na primeira colheita, quando tôdas as outras já rendiam mais de $30 \%$ da colheita total, o Maragogipe apenas dava 13,06\% (20 a 27 de março); na segunda colh eita é que essa variedade apresentou percentagem grande de frutos maduros $(54,35 \%)$ ficando, porém, na árvore, bem mais café do que nas outras variedades.

c) Tamanho das sementes - Foi feito o estudo da peneira média (2) para a primeira e segunda colheitas, que representam, em geral, a quase totalidade da produção. Os resultados foram os seguintes:

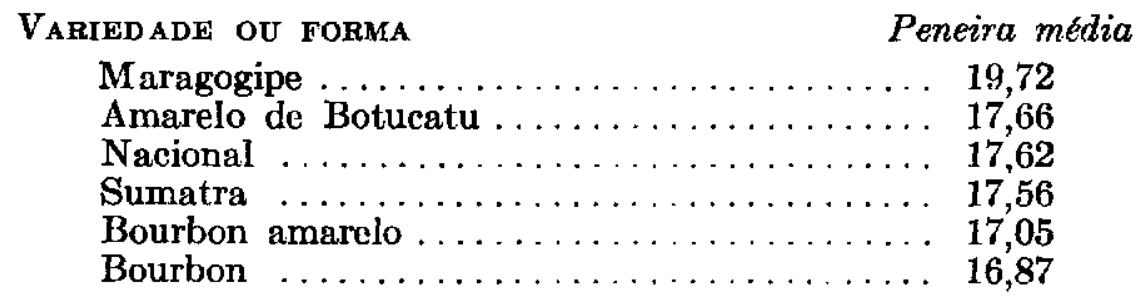

E flagrante a diferença entre o Maragogipe e as demais variedades ; - Amarelo de Botucatu, Nacional e Sumatra apresentam peneiras muito aproximadas; finalmente os dois Bourbons deram as menores sementes.

\section{2-COLHEITA DE 1940}

a) Produção total - A produção dêsse ano foi das melhores obtidas no decorrer dêste ensaio. O quadro 3 dá a indicação de como se comportaram as variedades. 
QUADRo 3.-Produções médias das variedades em 1940

\begin{tabular}{|c|c|c|c|}
\hline \multirow{2}{*}{ Variedade ou forma } & \multicolumn{3}{|c|}{ Produção de café } \\
\hline & Cereja & Em côco & Beneficiado \\
\hline & $k g$ & $k g$ & $\mathrm{~kg}$ \\
\hline Bourbon Amarelo & 372,720 & 180,560 & 89,480 \\
\hline Bourbon $\ldots \ldots \ldots$ & 359,800 & 170,400 & 84,090 \\
\hline Sumatra $\ldots \ldots \ldots \ldots$ & 348,640 & 165,520 & 83,480 \\
\hline Maragogipe. & 244,540 & 140,020 & 71,200 \\
\hline Nacional . . . . . . . . . & 291,040 & 138,180 & 69,500 \\
\hline Amarelo de Botucatu & 260,780 & 124,780 & 62,600 \\
\hline
\end{tabular}

Como fizemos anteriormente, tomamos por base, para a comparação das variedades, a produção do café em côco. O pêso do café cereja tem servido sòmente como medida de precaução, para a verificação do pêso do café em casca. No presente ano é evidente a disparidade entre a produção de café cereja da variedade Maragogipe e a das demais. E que esta variedade, sendo mais tardia, teve a maioria de seus frutos colhidos na segunda e terceira colheitas, quando já se achavam mais secos que os das outras variedades que tiveram a primeira e segunda colheitas bem maiores.

O Bourbon amarelo, Bourbon e Sumatra produziram sensivelmente mais que as três outras variedades. Neste ano, como no anterior, o Maragogipe colocou-se acima do Nacional e do Amarelo de Botucatu.

b) Época da maturação dos frutos - Foram feitas três colheitas, nas seguintes épocas: $1{ }^{a}$ colheita -8 a 18 de abril ; $2{ }^{a}$ colheita -16 a 22 de maio; $3 .^{a}$ colheita - 22 a 26 de julho.

As percentagens de café cereja colhido de cada uma das vêzes nos indicam o processo de amadurecimento para cada uma das variedades (quadro 4).

Quadro 4.-Produções e percentagens de café cereja nas diversas colheitas das variedades em 1940

Variedade ou forma

Amarelo de Botucatu .......

Nacional

Produções de café cereja

Sumatra . . . . . . . . . . . . . .

Bourbon ..................

Bourbon amarelo ..........

Maragogipe

\begin{tabular}{|c|c|c|c|c|c|}
\hline \multicolumn{6}{|c|}{ Produções de café cereja } \\
\hline \multicolumn{3}{|c|}{ Em pêso } & \multicolumn{3}{|c|}{ Em percentagem } \\
\hline $\begin{array}{l}\text { orimeira } \\
\text { colheita }\end{array}$ & $\begin{array}{l}\text { segunda } \\
\text { colheita }\end{array}$ & $\begin{array}{l}\text { terceira } \\
\text { colheita }\end{array}$ & $\begin{array}{l}\text { primeira } \\
\text { colheita }\end{array}$ & $\begin{array}{l}\text { segunda } \\
\text { colheita }\end{array}$ & $\begin{array}{l}\text { terceira } \\
\text { colheita }\end{array}$ \\
\hline$k g$ & $k g$ & $k g$ & $\%$ & $\%$ & $\%$ \\
\hline $\begin{array}{l}55,940 \\
45,760 \\
58,660 \\
58,820 \\
62,220\end{array}$ & $\begin{array}{r}160,780 \\
189,260 \\
203,300 \\
198,940 \\
194,960 \\
81,580\end{array}$ & $\begin{array}{r}44,060 \\
56,020 \\
83,680 \\
102,040 \\
115,540 \\
162,960\end{array}$ & $\begin{array}{l}21,45 \\
15,72 \\
16,82 \\
16,34 \\
16,69\end{array}$ & $\begin{array}{l}61,65 \\
65,02 \\
58,31 \\
55,29 \\
52,30 \\
33,36\end{array}$ & $\begin{array}{l}16,89 \\
19,24 \\
24,83 \\
28,36 \\
30,99 \\
66,96\end{array}$ \\
\hline
\end{tabular}


Adotando-se o critério de se colocarem as variedades pelas percentagens das produções obtidas na primeira e segunda colheitas, verifica-se que foi o Amarelo de Botucatu que apresentou maturação maior em maio $(83,10 \%)$, seguido de perto pelo Nacional $(80,74 \%)$.

Em seguida vem o Sumatra $(75,13 \%)$; depois o Bourbon $(71,63 \%)$ e Bourbon Amarelo (68,99\%). Como sempre, o Maragogipe produziu mais tardiamente ; na primeira colheita ainda não apresentava frutos maduros em quantidade apreciável para se fazer a operação e, na segunda, apenas apresentou $33,36 \%$ de cerejas.

c) Tamanho das sementes - A relação que se segue dá as peneiras médias apresentadas pelas diferentes variedades.

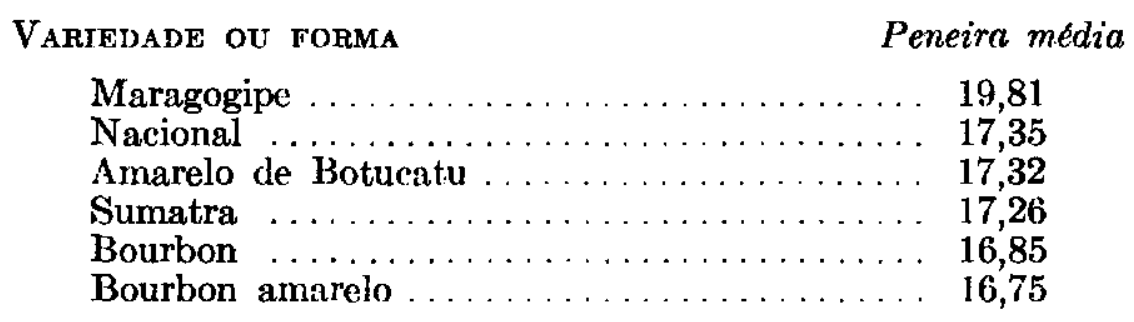

De novo o Maragogipe produziu as maiores sementes; o grupo constituído pelo Nacional, Amarelo de Botucatu e Sumatra apresentou peneiras médias muito aproximadas umas das outras, e, finalmente, ambos os Bourbons deram o menor tamanho de sementes.

\section{3-COLHEITA DE 1941}

a) Produção total - As produções dêste ano foram muito pequenas. Foi mesmo um dos piores anos verificados durante a existência do ensaio. A causa foi a sêca excessivamente prolongada de 1940. O quadro 5 demonstra como se comportaram as variedades.

Qvabno 5.-Produções médias das variedades em 1941

\begin{tabular}{|c|c|c|c|}
\hline \multirow{2}{*}{ Variedade ou forma } & \multicolumn{3}{|c|}{ Produção de café } \\
\hline & Cereja & Em côco & Beneficiado \\
\hline & $k g$ & $k g$ & $k g$ \\
\hline Bourbon Amarelo & 122,140 & 51,980 & 22,630 \\
\hline Bourbon . . . . . . & 109,020 & 47,400 & 20,210 \\
\hline Maragogipe. . . . . . & 65,840 & 31,040 & 14,380 \\
\hline Sumatra . . . . . . & 60,580 & 24,900 & 11,700 \\
\hline Ainarelo de Botucatu & 51,950 & 22,120 & 10,030 \\
\hline Nacional . . . . . . . . & 46,300 & 19,500 & 9,150 \\
\hline
\end{tabular}

O primeiro lugar cabe aos dois Bourbons ; depois a produção cai muito, colocando-se a variedade Maragogipe logo após aquêles ; finalmente, aparecem, em ordem decrescente, o Sumatra, o Amarelo de Botucatu e o Nacional. 
A variedade Maragogipe vem produzindo mais que o Nacional e o Amarelo de Botucatu, desde 1939 (1939, 1940 e 1941).

b) Epoca de maturação dos frutos - Foi continuada a determinação da maturação de cada uma das variedades. Foram executadas três colheitas, a saber : $1 .^{\mathrm{a}}$ colheita -8 a 16 de abril ; $2 .^{\mathrm{a}}$ colheita -5 a 9 de maio; $3 .^{2}$ colheita -14 a 16 de junho.

Os resultados que aparecem no quadro 6 dão uma idéia de como se processou o amadurecimento nas diversas variedades.

Quadro 6.-Produções e percentagens de café cereja nas diversas colheitas das variedades em 1941

\begin{tabular}{|c|c|c|c|c|c|c|}
\hline \multirow{3}{*}{ Variedade ou forma } & \multicolumn{6}{|c|}{ Produções de café cereja } \\
\hline & \multicolumn{3}{|c|}{ Em pêso } & \multicolumn{3}{|c|}{ Em percentagem } \\
\hline & $\begin{array}{c}\text { primeira } \\
\text { colheita }\end{array}$ & $\begin{array}{l}\text { segunda } \\
\text { colheita }\end{array}$ & $\begin{array}{l}\text { terceira } \\
\text { colheita }\end{array}$ & $\begin{array}{l}\text { primeira } \\
\text { colheita }\end{array}$ & $\begin{array}{l}\text { segunda } \\
\text { colheita }\end{array}$ & $\begin{array}{l}\text { terceira } \\
\text { colheita }\end{array}$ \\
\hline & $k g$ & $k g$ & $k g$ & $\%$ & $\%$ & $\%$ \\
\hline $\begin{array}{l}\text { Amarelo de Botucatu } \ldots \ldots \\
\text { Sumatra } \ldots \ldots \ldots \\
\text { Nacional } \ldots \ldots \ldots \ldots \ldots \\
\text { Bourbon } \ldots \ldots \ldots \ldots \\
\text { Bourbon amarelo } \ldots \ldots \ldots \\
\text { Maragogipe } \ldots \ldots \ldots\end{array}$ & $\begin{array}{c}31,280 \\
40,660 \\
27,660 \\
62,880 \\
57,340 \\
\cdots\end{array}$ & $\begin{array}{l}18,620 \\
16,320 \\
15,720 \\
37,980 \\
16,320 \\
40,780\end{array}$ & $\begin{array}{r}2,050 \\
3,600 \\
2,920 \\
8,160 \\
3,600 \\
25,060\end{array}$ & $\begin{array}{l}60,20 \\
67,11 \\
59,74 \\
57,67 \\
46,94 \\
\cdots\end{array}$ & $\begin{array}{l}35,84 \\
26,93 \\
33,95 \\
34,83 \\
41,72 \\
61,93\end{array}$ & $\begin{array}{r}3,94 \\
5,94 \\
6,30 \\
7,48 \\
11,33 \\
38,06\end{array}$ \\
\hline
\end{tabular}

$\mathrm{Na}$ primeira colheita, o Maragogipe ainda não tinha café maduro suficiente para que se fizesse a operação. Verifica-se, portanto, que esta variedade, êste ano, de novo, é pelo menos um mês mais tardia que as demais. Se reunirmos a primeira e segunda colheitas, vamos encontrar o seguinte resultado : o Amarelo de Botucatu, o que maior percentagem de café apresentou $(96,04 \%)$, seguido muito de perto pelo Sumatra $(94,04 \%)$, Nacional $(93,69 \%)$ e Bourbon $(92,52 \%)$; o Bourbon amarelo amadureceu menos ràpidamente, dando, nessa ocasião, $88,66 \%$ de frutos maduros.

c) Tamanho das sementes - $O$ cálculo da peneira média para as diversas variedades vem expresso na relação seguinte :

VARIEDADE OU FORMA

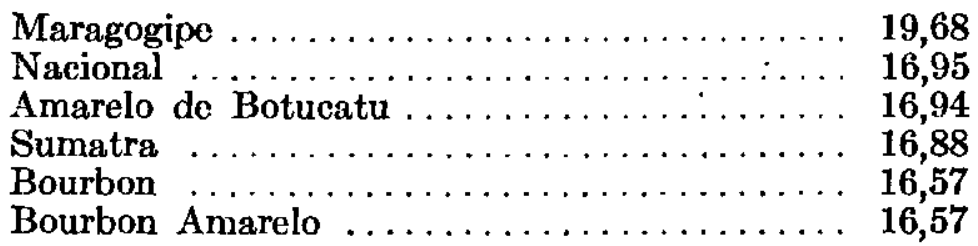

De novo, o tamanho da semente do Maragogipe é sensivelmente maior do que o das demais ; o Nacional e o Amarelo de Botucatu apresentaram peneira média pràticamente idêntica ; abaixo dêstes vem o Sumatra, e, em último lugar, ambos os Bourbons. 
E interessante notar que tôdas as variedades produziram peneiras menores do que as do ano anterior.

\section{4-COLHEITA DE 1942}

a) Produção total - De um modo geral, a produção neste ano foi bem maior no ensaio de variedades. No quadro 7 especificamos os resultados obtidos.

Quadro 7.-Produções médias das variedades em 1942

\begin{tabular}{|c|c|c|c|}
\hline \multirow{2}{*}{ Variedade ou forma } & \multicolumn{3}{|c|}{ Produção de café } \\
\hline & Cereja & Em côco & Beneficiado \\
\hline & $k g$ & $k g$ & $k g$ \\
\hline Bourbon amarelo & 216,440 & 114,930 & 60,650 \\
\hline Bourbon ........ & 209,020 & 110,060 & 57,880 \\
\hline Sumatra ......... & 197,740 & 96,340 & 51,030 \\
\hline Amarelo de Botucatu & 162,160 & 78,250 & 41,560 \\
\hline Nacional ........... & 135,580 & 66,540 & 35,770 \\
\hline Maragogipe. . . . . . . & 95,640 & 63,600 & 35,020 \\
\hline
\end{tabular}

Verificam-se os seguintes fatos: 1) a notável superioridade de ambos os Bourbons ; 2) boa produção do Sumatra ; 3) produção baixa do Amarelo de Botucatu e do Nacional ; 4) a pequena produção do Maragogipe que, de novo, volta a ocupar o último lugar.

b) Época da maturação dos frutos - Foram feitas três colheitas, a saber : $1 .^{\mathrm{a}}$ colheita -9 a 14 de março ; $2 .^{a}$ colheita -14 a 27 de abril ; 3. ${ }^{\text {a }}$ colheita -31 de julho a 6 de agôsto.

A percentagem de frutos colhidos em cada uma dessas colheitas é dada no quadro 8.

Quadro 8.-Produções e percentagens de café cereja nas diversas colheitas das variedades em 1942

\begin{tabular}{|c|c|c|c|c|c|c|}
\hline \multirow{3}{*}{ Variedade ou forma } & \multicolumn{6}{|c|}{ Produções de café cereja } \\
\hline & \multicolumn{3}{|c|}{ Em pêso } & \multicolumn{3}{|c|}{ Em percentagem } \\
\hline & $\begin{array}{l}\text { primeira } \\
\text { colheita }\end{array}$ & $\begin{array}{l}\text { segunda } \\
\text { colheita }\end{array}$ & $\begin{array}{l}\text { terceira } \\
\text { colheita }\end{array}$ & $\begin{array}{l}\text { primeira } \\
\text { colheita }\end{array}$ & $\begin{array}{l}\text { segunda } \\
\text { colheita }\end{array}$ & $\begin{array}{l}\text { terceira } \\
\text { colheita }\end{array}$ \\
\hline & $k g$ & $k g$ & $k g$ & $\%$ & $\%$ & $\%$ \\
\hline $\begin{array}{l}\text { Amarelo de Botucatu } \ldots \ldots \\
\text { Nacional } \ldots \ldots \ldots \ldots \\
\text { Sumatra } \ldots \ldots \ldots \ldots \ldots \\
\text { Bourbon } \ldots \ldots \ldots \ldots \ldots \\
\text { Bourbon amarelo } \ldots \ldots \ldots \ldots \\
\text { Maragogipe } \ldots \ldots \ldots \ldots \ldots \\
\end{array}$ & $\begin{array}{l}34,400 \\
30,000 \\
36,360 \\
20,040 \\
20,220\end{array}$ & $\begin{array}{r}96,080 \\
76,840 \\
118,600 \\
122,260 \\
114,800 \\
20,720\end{array}$ & $\begin{array}{l}31,680 \\
28,740 \\
42,780 \\
66,720 \\
81,420 \\
74,920\end{array}$ & $\begin{array}{r}21,21 \\
22,13 \\
18,39 \\
9,59 \\
9,32 \\
\cdots\end{array}$ & $\begin{array}{l}59,25 \\
56,67 \\
59,49 \\
58,49 \\
53,04 \\
21,66\end{array}$ & $\begin{array}{l}19,54 \\
21,20 \\
21,63 \\
31,92 \\
37,62 \\
78,34\end{array}$ \\
\hline
\end{tabular}


O Amarelo de Botucatu, o Nacional e o Sumatra foram os mais precoces; os dois Bourbons vêm em seguida e, finalmente, o Maragogipe que, como sempre, se atrasou mais ou menos um mês com relação às demais variedades.

c) Tamanho das sementes - $\mathrm{O}$ cálculo da peneira média, para as diferentes variedades, é o seguinte:

VARIEDADE OU FORMA

Peneira média

Maragogipe ................... 19,50

Amarelo de Botucatu............. 17,52

Nacional $\ldots \ldots \ldots \ldots \ldots \ldots \ldots \ldots \ldots, 17,44$

Sumatra $\ldots \ldots \ldots \ldots \ldots \ldots \ldots \ldots \ldots$ 17,37

Bourbon ...................... 17,12

Bourbon amarelo................17,12

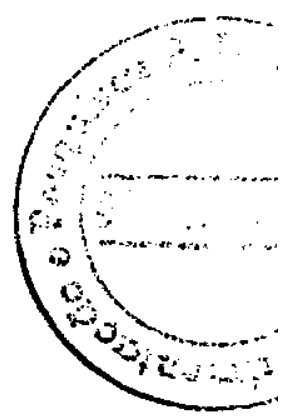

O Maragogipe apresentou as maiores sementes ; em segundo lugar vem - Amarelo de Botucatu, que, neste ano, se distanciou do Nacional ; depois dêste vem o Sumatra e, finalmente, com peneira idêntica, ambos os Bourbons.

\section{5-COLHEITA DE 1943}

a) Produção total - $\mathrm{O}$ ano agrícola decorreu em condições péssimas para a lavoura cafeeira. Em 1942 houve uma geada que, apesar de não haver queimado as plantas do ensaio, prejudicou grandemente os cafeeiros, agravando a situação criada pela sêca dêsse mesmo ano. As produções foram, em geral, menores, para as variedades em exame, à exceção do Maragogipe.

O quadro 9 demonstra as produçóes das diversas variedades.

Quadro 9.-Produções médias das variedades em 1943

\begin{tabular}{|c|c|c|c|}
\hline \multirow{2}{*}{ Variedade ou forma } & \multicolumn{3}{|c|}{ Produção de café } \\
\hline & Cereja & Em côco & Beneficiado \\
\hline & $k g$ & $k g$ & $k g$ \\
\hline Bourbon amarelo & 216,900 & 97,580 & 47,270 \\
\hline Bourbon ......... & 179,700 & 80,180 & 38,480 \\
\hline Sumatra $\ldots \ldots \ldots$ & 174,700 & 77,520 & 38,810 \\
\hline Maragogipe. & 147,420 & 73,300 & 36,590 \\
\hline Nacional ........... & 135,660 & 61,500 & 30,930 \\
\hline Amarelo de Botucatu & 99,600 & 45,240 & 22,190 \\
\hline
\end{tabular}

E evidente, neste ano, a superioridade do Bourbon amarelo. O Bourbon e Sumatra mantêm-se quase em nivel idêntico. $O$ Maragogipe colocou-se em quarto lugar, vindo, em penúltimo e último, respectivamente, o Nacional e o Amarelo de Botucatu. 
b) Epoca da maturação dos frutos - A colheita foi feita em três épocas : 1.* colheita - 12 a 15 de maio ; $2 .^{n}$ colheita -22 a 26 de junho ; 3." colheita -4 a 9 de agôsto.

0 quadro 10 dá o andamento da maturação nas diferentes variedades.

QuAdro 10.-Produçzes e percentagens de café cereja nas diversas colheitas das variedades em 1943

\begin{tabular}{|c|c|c|c|c|c|c|}
\hline \multirow{3}{*}{ Variedade ou forma } & \multicolumn{6}{|c|}{ Produçōes de café cereja } \\
\hline & \multicolumn{3}{|c|}{ Em pêso } & \multicolumn{3}{|c|}{ Em percentagem } \\
\hline & $\begin{array}{l}\text { primeira } \\
\text { colheita }\end{array}$ & $\begin{array}{l}\text { segunda } \\
\text { colheita }\end{array}$ & $\begin{array}{l}\text { terceira } \\
\text { colheita }\end{array}$ & $\begin{array}{l}\text { primeira } \\
\text { colheita }\end{array}$ & $\begin{array}{l}\text { segunda } \\
\text { colheita }\end{array}$ & $\begin{array}{l}\text { terceira } \\
\text { colheita }\end{array}$ \\
\hline & $k g$ & $k g$ & $k g$ & $\%$ & $\%$ & $\%$ \\
\hline $\begin{array}{l}\text { Amarelo de Botucatu } \ldots \ldots \\
\text { Sumatra } \ldots \ldots \\
\text { Nacional } \ldots \ldots \ldots \\
\text { Bourbon } \ldots \ldots \ldots \ldots \\
\text { Bourbon amarelo } \ldots \ldots \ldots \\
\text { Maragogipe } \ldots \ldots \ldots \\
\end{array}$ & $\begin{array}{r}68,880 \\
115,100 \\
86,900 \\
87,880 \\
97,360 \\
\cdots\end{array}$ & $\begin{array}{l}27,400 \\
52,040 \\
43,520 \\
76,540 \\
91,500 \\
84,080\end{array}$ & $\begin{array}{r}3,320 \\
7,560 \\
\mathbf{5 , 2 4 0} \\
15,280 \\
28,040 \\
63,340\end{array}$ & $\begin{array}{l}69,15 \\
65,88 \\
64,06 \\
48,90 \\
44,89\end{array}$ & $\begin{array}{l}27,51 \\
29,79 \\
32,08 \\
42,59 \\
42,18 \\
57,03\end{array}$ & $\begin{array}{r}3,33 \\
4,33 \\
3,86 \\
8,50 \\
12,93 \\
42,96\end{array}$ \\
\hline
\end{tabular}

De novo, o Amarelo de Botucatu se mostrou mais precoce ; o Sumatra e o Nacional pràticamente amadureceram igualmente; os dois Bourbons foram mais tardios, sendo apenas superados pelo Maragogipe.

c) Tamanho das sementes - O cálculo da peneira média deu os resultados seguintes :

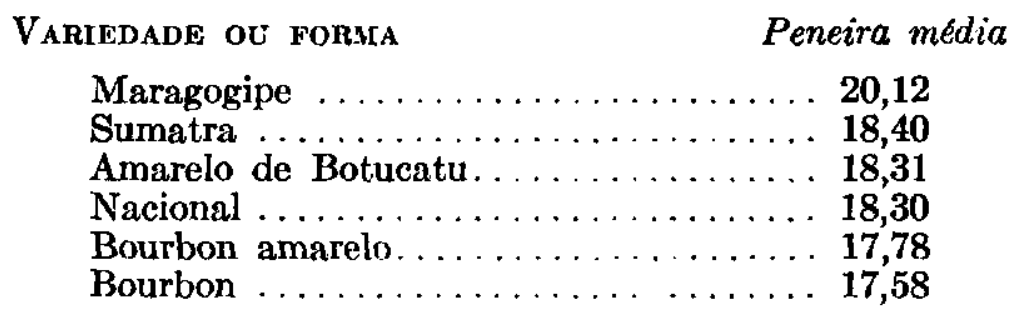

Como em todos os anos anteriores, o Maragogipe produziu o café de maior tamanho; o Sumatra vem logo em seguida, com uma peneira média bastante elevada ; o Amarelo de Botucatu e o Nacional deram produto quase idêntico $\mathrm{e}$, finalmente, foram bem menores as sementes apresentadas pelo Bourbon amarelo e Bourbon.

\section{6-COLHEITA DE 1944}

a) Produção total - As condições meteorológicas reinantes no ano agrícola foram muito desfavoráveis. Em setembro de 1943, repetiu-se a geada, e o ano de 1944 foi o mais sêco de que há notícias nos registos meteorológicos do Instituto Agronômico, para Campinas. A produção não foi das menores, em virtude de, no ano de 1943, o total de chuvas ter-se apro- 
ximado da média. Os resultados obtidos com as diversas variedades vêm expressos no quadro 11.

Quadro 11.-Produções médias das variedades em 1944

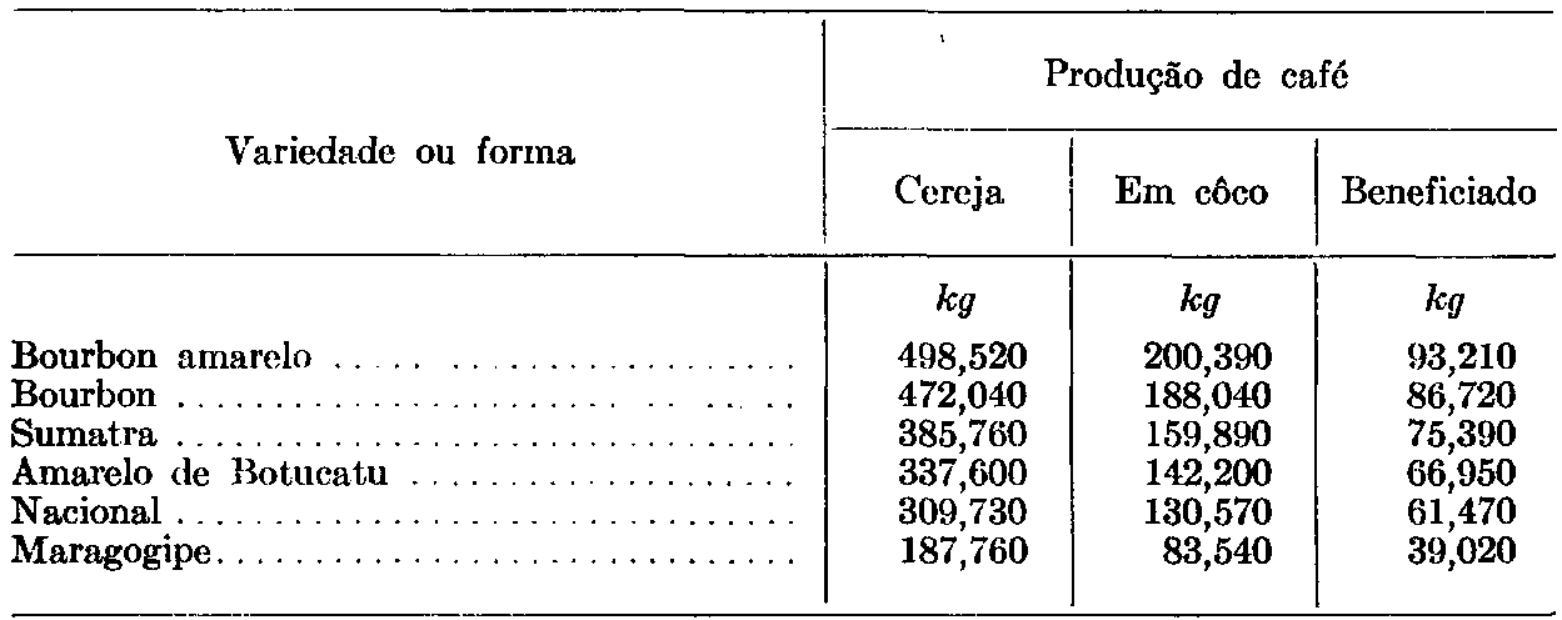

E incontestável a superioridade dos dois Bourbons; há, neste ano, uma escala descendente de produção bem marcada entre o Sumatra, Amarelo de Botucatu e Nacional ; o Maragogipe produziu bem menos que qualquer das outras variedades ensaiadas.

b) Época da maturação dos frutos - A colheita foi executada em três vêzes : $1 .^{\text {a }}$ colheita -10 a 18 de abril ; $2 .^{\text {a }}$ colheita -13 a 22 de maio ; 3." colheita - 17 a 21 de junho.

O quadro 12 dá o café colhido em cada uma das vêzes e a percentagem apresentada sôbre o total colhido.

Quadro 12.-Produções e percentagens de café cercja nas diversas colheitas das variedades em 1944

Variedade ou forma

Amarelo de Botucatu .......

Nacional ................

Sumatra $\ldots \ldots \ldots \ldots \ldots . .$.

Bourbon .................

Bourbon amarelo .............

Maragogipe ................

\begin{tabular}{c|c|c|c|c|c}
\multicolumn{5}{c|}{ Produção de café cereja } \\
\hline \multicolumn{3}{c|}{ Lm pêso } & \multicolumn{3}{c}{ Fm percentagem } \\
\hline $\begin{array}{c}\text { primeira } \\
\text { colheita }\end{array}$ & $\begin{array}{c}\text { segunda } \\
\text { colheita }\end{array}$ & $\begin{array}{c}\text { terceira } \\
\text { colheita }\end{array}$ & $\begin{array}{c}\text { primeira } \\
\text { colheita }\end{array}$ & $\begin{array}{c}\text { segunda } \\
\text { colheita }\end{array}$ & $\begin{array}{c}\text { terceira } \\
\text { colheita }\end{array}$ \\
\hline$k g$ & $k g$ & $k g$ & $\%$ & $\%$ & $\%$ \\
224,500 & 91,120 & 21,980 & 66,49 & 26,99 & 6,51 \\
198,220 & 88,320 & 23,220 & 63,99 & 28,51 & 7,49 \\
237,780 & 108,060 & 39,920 & 61,63 & 28,01 & 10,34 \\
243,100 & 176,380 & 52,560 & 51,49 & 37,36 & 11,13 \\
213,620 & 192,560 & 92,340 & 42,85 & 38,62 & 18,52 \\
$\ldots \ldots$ & 135,340 & 52,420 & $\ldots$ & 72,08 & 27,91 \\
& & & & & \\
\hline
\end{tabular}

O Amarelo de Botucatu e o Nacional amadureceram pràticamente de modo idêntico; o Sumatra apresentou percentagens muito aproximadas 
daqueles ; os dois Bourbons foram mais tardios, principalmente o amarelo ; - Maragogipe, como em todos os anos anteriores, foi o que amadureceu mais tarde.

c) Tamanho das sementes - $O$ exame das sementes produzidas pelas diversas variedades, relativamente ao tamanho, deu os seguintes resultados :

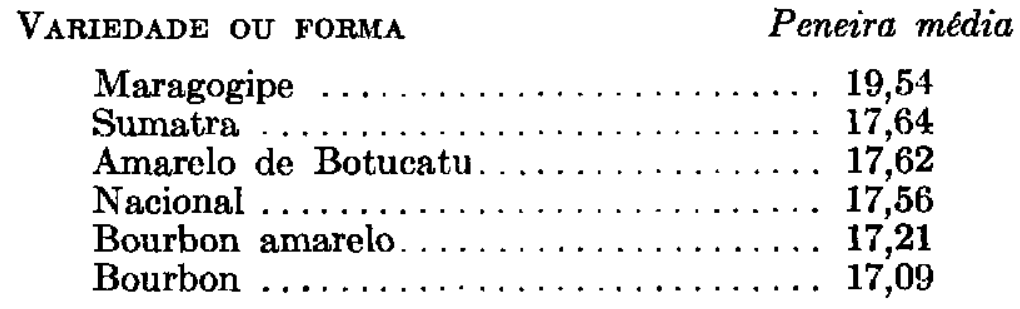

Como anteriormente, o Maragogipe apresentou as maiores sementes ; em segundo lugar veio o Sumatra, seguido muito de perto pelo Amarelo de Botucatu ; em quarto lugar aparece o Nacional e, finalmente, com as menores sementes, se apresentam ambos os Bourbons.

\section{7-COLHEITA DE 1945}

a) Produção total - As produções verificadas em cada uma das variedades vêm expressas no quadro 13.

Quadro 13.--Produçōes médias das variedades em 1944

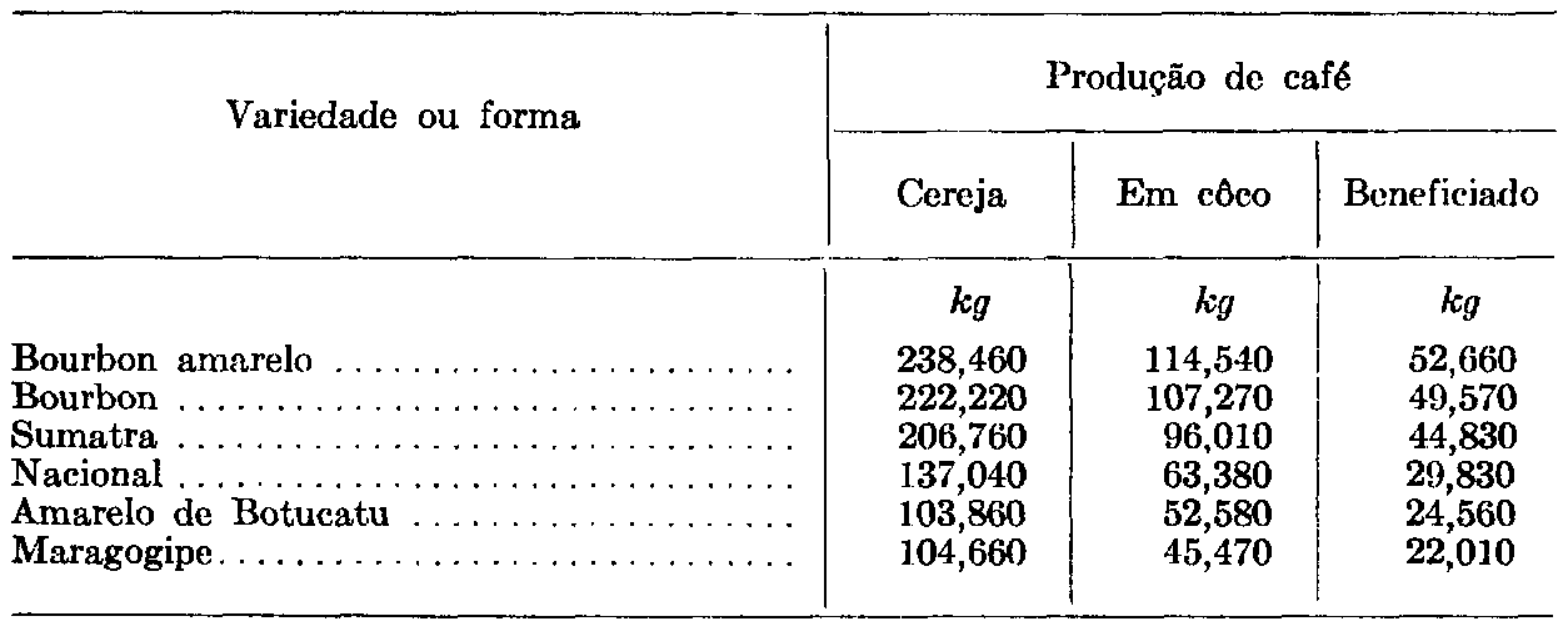

A maior produção é, sem dúvida alguma, apresentada pelos dois Bourbons; em seguida vem o Sumatra, com boa superioridade sôbre as três variedades restantes; em último lugar ficou o Maragogipe.

b) Época da maturação dos frutos - Como nos anos anteriores, a colheita se processou em três épocas, a saber : $1 .^{2}$ colheita - 19 a 26 de maio ; $2 .^{a}$ colheita - 12 a 14 de junho ; $3 .^{a}$ colheita -10 a 11 de agôsto.

As percentagens de frutos maduros em cada uma dessas ocasióes vêm no quadro 14. 
Quadro 14.-Produções e percentagens de café cereja nas diversas colheitas das variedades em 1945

\begin{tabular}{|c|c|c|c|c|c|c|}
\hline \multirow{3}{*}{ Variedade ou forma } & \multicolumn{6}{|c|}{ Produção de café cereja } \\
\hline & \multicolumn{3}{|c|}{ Em pêso } & \multicolumn{3}{|c|}{ Em percentagem } \\
\hline & $\begin{array}{l}\text { primeira } \\
\text { colheita }\end{array}$ & $\begin{array}{l}\text { segunda } \\
\text { colheita }\end{array}$ & $\begin{array}{l}\text { terceira } \\
\text { colheita }\end{array}$ & $\begin{array}{l}\text { primeira } \\
\text { colheita }\end{array}$ & $\begin{array}{l}\text { segunda } \\
\text { colheita }\end{array}$ & $\begin{array}{l}\text { terceira } \\
\text { colheita }\end{array}$ \\
\hline & $k g$ & $k g$ & $k g$ & $\%$ & $\%$ & $\%$ \\
\hline $\begin{array}{l}\text { Amarelo de Botucatu } \ldots \ldots \\
\text { Sumatra } \ldots \ldots \ldots \ldots \\
\text { Nacional } \ldots \ldots \ldots \ldots \\
\text { Bourbon } \ldots \ldots \ldots \ldots \\
\text { Bourbon amarelo } \ldots \ldots \ldots \ldots \\
\text { Maragogipe } \ldots \ldots \ldots \ldots \\
\end{array}$ & $\begin{array}{r}101,420 \\
200,740 \\
132,960 \\
208,260 \\
220,060 \\
81,760\end{array}$ & $\begin{array}{r}2,140 \\
5,360 \\
3,560 \\
12,440 \\
15,240 \\
17,540\end{array}$ & $\begin{array}{l}0,300 \\
0,660 \\
0,520 \\
1,520 \\
3,160 \\
5,360\end{array}$ & $\begin{array}{l}97,65 \\
97,08 \\
97,02 \\
93,71 \\
92,28 \\
78,11\end{array}$ & $\begin{array}{r}2,06 \\
2,59 \\
2,59 \\
5,59 \\
6,39 \\
16,75\end{array}$ & $\begin{array}{l}0,28 \\
0,31 \\
0,37 \\
0,68 \\
1,32 \\
5,12\end{array}$ \\
\hline
\end{tabular}

A primeira colheita neste ano foi efetuada muito tarde, o que dificultou a verificação do modo de se processar o amadurecimento nas diversas variedades. No entanto, é fácil de se ver que o Maragogipe é a variedade mais tardia.

c) "Tamanho das sementes - Na relação que se segue vem expressa a peneira média apresentada pelas diversas variedades.

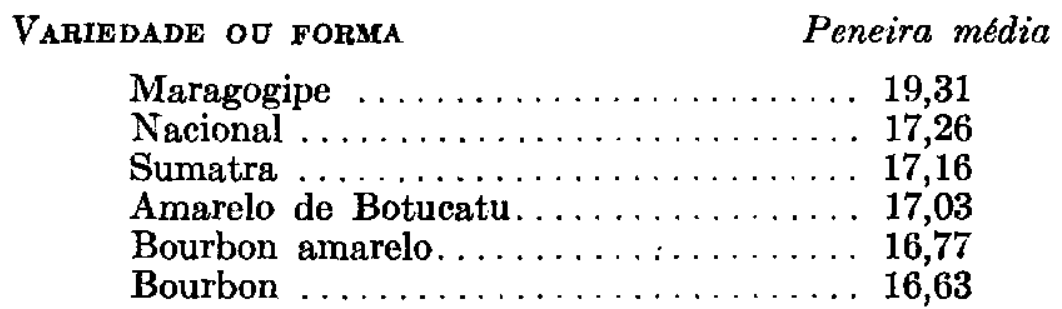

\section{8-COLHEITA DE 1946}

a) Produção total - Os resultados da colheita dêste ano vêm expressos no quadro 15.

Quadro 15.-Produções médias das variedades em 1946

Variedade ou forma

Bourbon amarelo

Maragogipe

Bourbon

Sumatra

\begin{tabular}{c|c|c}
\multicolumn{3}{c}{ Produção de café } \\
\hline Cereja & Em côco & Beneficiado \\
\hline$k g$ & $k g$ & $k g$ \\
499,940 & 226,200 & 113,830 \\
436,900 & 188,000 & 96,920 \\
389,380 & 178,640 & 88,530 \\
340,280 & 160,880 & 80,820 \\
257,260 & 122,400 & 61,340 \\
243,540 & 119,120 & 59,640 \\
& & \\
\hline
\end{tabular}


Neste ano há o fato notável de que, pela primeira vez, em todo o decurso da experiência, tenha sido um dos Bourbons sobrepujado pelo Maragogipe.

b) Epoca da maturação dos frutos - Neste ano, por dificuldade em obter pessoal operário suficiente, houve apenas duas colheitas : a primeira, de 29 de maio a 10 de junho e, a segunda, de 17 a 22 de julho.

As percentagens de frutos maduros, em cada uma delas, vêm expressas no quadro 16.

QUADro 16.-Produçōes e percentagens de cafe cereja nas duas colheitas das diversas variedades em 1946

\begin{tabular}{|c|c|c|c|c|}
\hline \multirow{3}{*}{ Variedade ou forma } & \multicolumn{4}{|c|}{ Produção de café cereja } \\
\hline & \multicolumn{2}{|c|}{ Em pêso } & \multicolumn{2}{|c|}{ Em percentagem } \\
\hline & $\begin{array}{l}\text { primeira } \\
\text { colheita }\end{array}$ & $\begin{array}{l}\text { segunda } \\
\text { colheita }\end{array}$ & $\begin{array}{l}\text { primeira } \\
\text { colheita }\end{array}$ & $\begin{array}{l}\text { segunda } \\
\text { colheita }\end{array}$ \\
\hline & $\operatorname{kg}$ & $k g$ & $\%$ & $\%$ \\
\hline Amarelo de Botucatu & 228,460 & 15,080 & 93,80 & 6,19 \\
\hline Nacional. . . . . . . . . . & 239,360 & 17,900 & 93,04 & 6,95 \\
\hline Sumatra $\ldots \ldots \ldots$ & 305,320 & 34,960 & 89,72 & 10,27 \\
\hline Bourbon anarelo & 415,040 & 84,900 & 83,01 & 16,98 \\
\hline Bourbon $\quad \ldots \ldots$ & 347,340 & 42,040 & 89,20 & 12,10 \\
\hline Maragogipe $\ldots \ldots \ldots \ldots \ldots \ldots \ldots$ & 339,280 & 97,620 & 77,65 & 22,34 \\
\hline
\end{tabular}

A primeira colheita foi feita muito tardiamente, o que não permite apreciar como se processou a maturação dos frutos. A ordem da colocação das variedades, porém, é a mesma da maioria dos anos examinados. Também neste ano a variedade Maragogipe se revelou bem mais tardia que as demais.

c) Tamanho das sementes - A seguir damos a relação média das peneiras obtidas na primeira colheita.

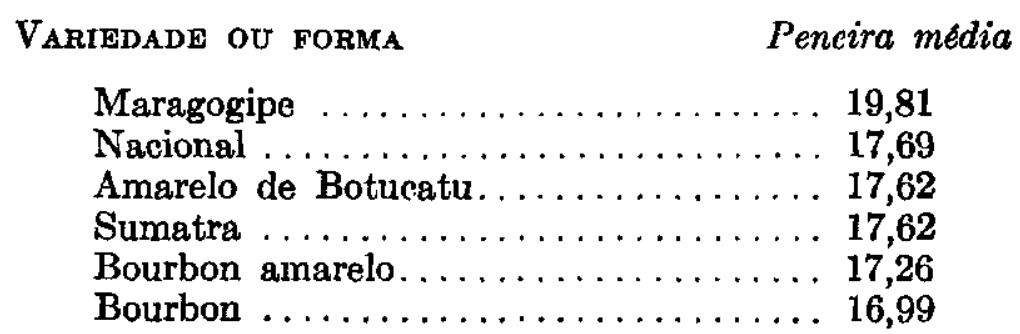

O Maragogipe, como sempre, apresentou a maior peneira média; vem em seguida o Nacional ; o Amarelo de Botucatu e o Sumatra deram sementes de igual tamanho; os dois Bourbons foram os que produziram menores sementes, havendo, no entanto, vantagem para o Bourbon amarelo. 


\begin{tabular}{|c|c|c|c|c|c|c|c|}
\hline 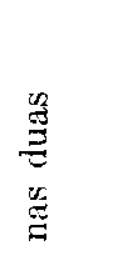 & 品 & 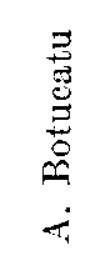 & 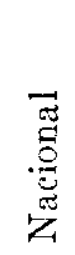 & 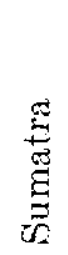 & 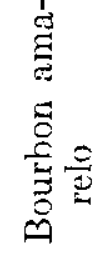 & 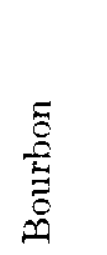 & 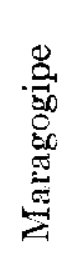 \\
\hline 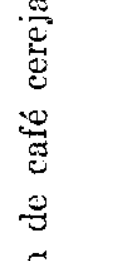 & $\stackrel{20}{\stackrel{D}{D}}$ & 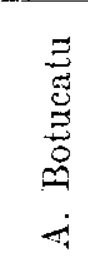 & 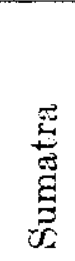 & 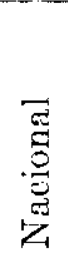 & 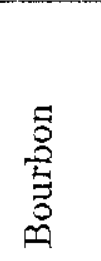 & 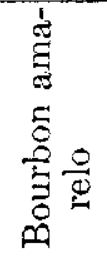 & 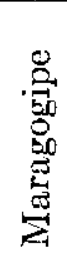 \\
\hline 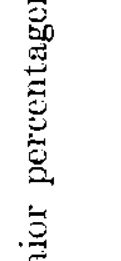 & $\underset{B}{\stackrel{H}{*}}$ & 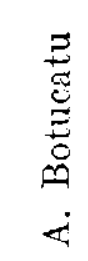 & 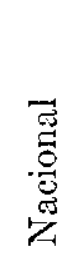 & 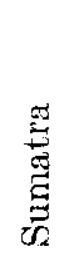 & 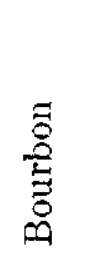 & 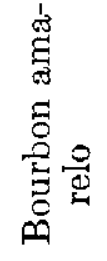 & 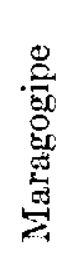 \\
\hline 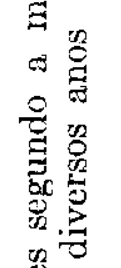 & 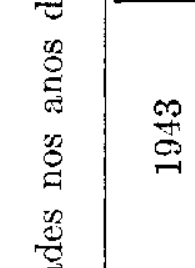 & 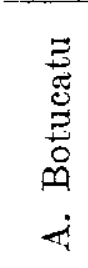 & 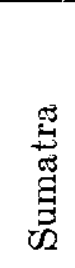 & 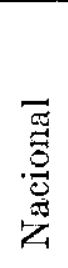 & 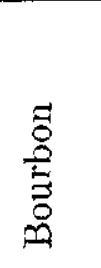 & 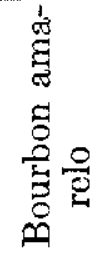 & 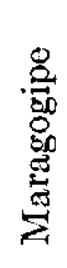 \\
\hline 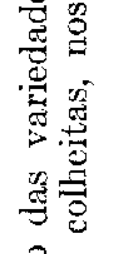 & 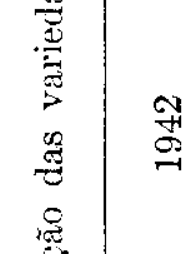 & 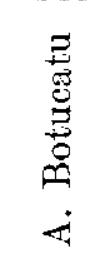 & 胥 & 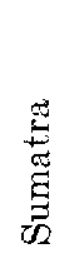 & 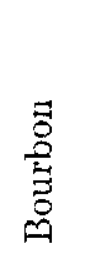 & 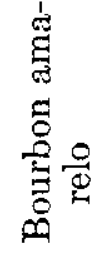 & 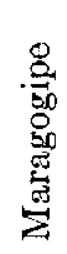 \\
\hline 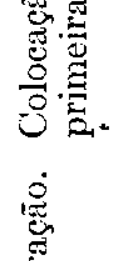 & 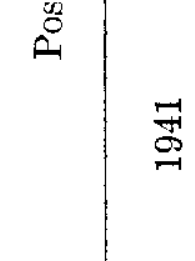 & 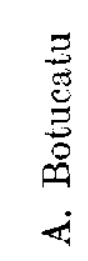 & 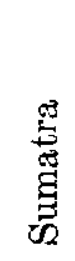 & 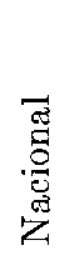 & 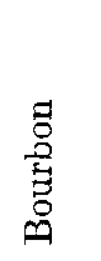 & 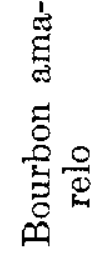 & 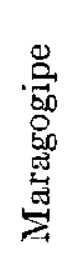 \\
\hline 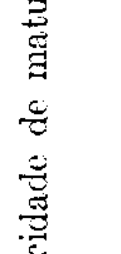 & 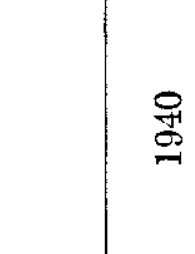 & 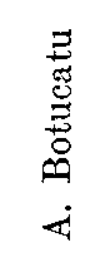 & 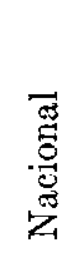 & 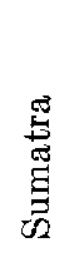 & 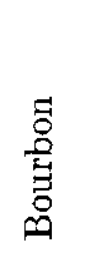 & 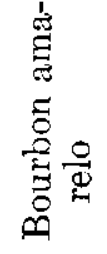 & 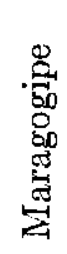 \\
\hline 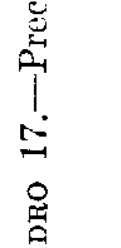 & $\underset{\mathscr{D}}{\mathscr{D}}$ & 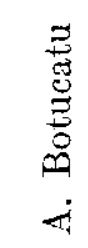 & 营 & 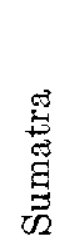 & 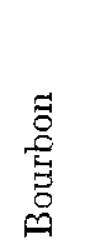 & 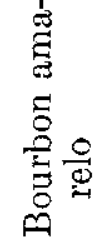 & 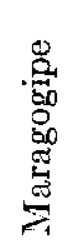 \\
\hline$\stackrel{\varpi}{\sigma}$ & 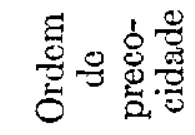 & $\tau$ & $\sim$ & $\infty$ & $\star$ & 20 & $\omega$ \\
\hline
\end{tabular}




\section{5-CONCLUSÕES}

\section{1-MATURAÇÃO DOS FRUTOS}

Examinando-se, ano por ano, como se verificou a maturação dos frutos nas variedades ensaiadas, alguns fatos se tornam bem evidentes. $O$ quadro 17 dá a relação das variedades, colocadas de acôrdo com a maior percentagem de frutos maduros obtidos na primeira e segunda colheitas, nos diversos anos do período examinado.

\section{Verifica-se que :}

a) o $\Lambda$ marelo de Botucatu foi a variedade mais precoce em todos os anos ;

b) o Nacional e o Sumatra alternaram entre si a segunda posição com relação à precocidade na maturação dos frutos;

c) os dois Bourbons são um pouco mais tardios que as variedades já citadas, principalmente o Bourbon amarelo;

d) o Maragogipe é a variedade mais tardia. Se estudarmos as datas do início de sua plena maturação, notaremos que leva cêrca de um mês a mais do que as outras variedades para atingir êsse período.

\section{2-TAMANHO DAS SEMENTES}

Estudando a peneira média das diversas variedades no período em exame, é possível também chegarmos a alguns resultados bem concludentes.

Quadro 18.-Valores de peneira média para as diversas variedades, determinados, ano por ano, no período 1939-46

\begin{tabular}{|c|c|c|c|c|c|c|c|c|c|}
\hline \multirow{2}{*}{ Variedade ou forma } & \multicolumn{9}{|c|}{ Pencira média nos anos } \\
\hline & 1939 & 1940 & 1941 & 1942 & 1943 & 1944 & 1945 & 1946 & Média \\
\hline Bourbon amarelo & 16,87 & 16,85 & 16,57 & 17,12 & 17,58 & 17,09 & 16,63 & 16,99 & 16,96 \\
\hline Bourbon $\ldots . .$. & 17,05 & 16,75 & 16,57 & 17,12 & 17,78 & 17,21 & 16,77 & 17,26 & 17,06 \\
\hline Sumatra & 17,56 & 17,26 & 16,88 & 17,37 & 18,40 & 17,64 & 17,16 & 17,62 & 17,49 \\
\hline Amarelo de Botucatu & 17,66 & 17,32 & 16,94 & 17,52 & 18,31 & 17,62 & 17,03 & 17,62 & 17,50 \\
\hline Nacional . . . . . . . & 17,62 & 17,35 & 16,95 & 17,44 & 18,30 & 17,56 & 17,26 & 17,69 & 17,52 \\
\hline Maragogipe . . & 19,72 & 19,81 & 19,68 & $19, \tilde{5} 0$ & 20,12 & 19,54 & 19,31 & 19,81 & 19,69 \\
\hline
\end{tabular}

\section{Verifica-se que :}

a) a variedade Maragogipe foi a que produziu sementes de maior tamanho $\mathrm{cm}$ todos os anos do período examinado;

b) os dois Bourbons foram as variedades que apresentaram menor tamanho de semente em todo o período considerado; 
c) as variedades Nacional, Sumatra e Amarelo de Botucatu se colocaram em situação intermediária entre a variedade Maragogipe e os dois Bourbons. O valor da peneira média das três variedades foi mais ou menos aproximado.

\section{3-PRODUÇÃO}

O quadro 19 dá a produção, em café em côco de tôdas as variedades, ano por ano, no período de 1935-1946.

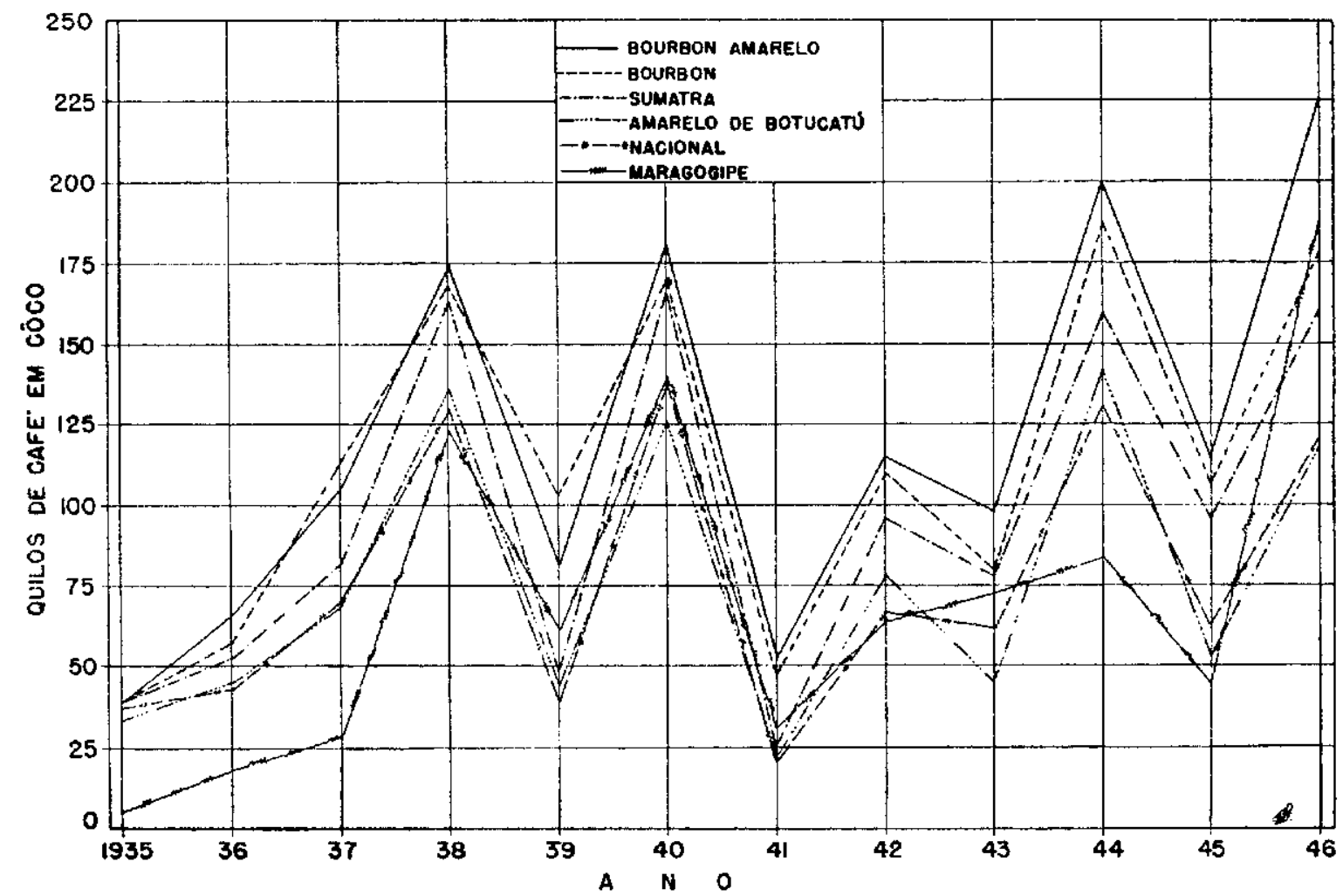

ligura 1,-Produção média anual, em $\mathrm{kg}$ de café em côco, de 50 cafeeiros de cada uma das variedades estudadas, no período 1935-1946.

Examinando-se o quadro 19 e a fig. 1 verifica-se que tôdas as variedades foram aumentando a produção de 1935 até 1938. Dá em diante, tôdas elas, com exceção do Maragogipe, depois de uma colheita grande, apresentaram sempre uma menor. O Maragogipe seguiu êsse mesmo ritmo no período de 1938 a 1942. Depois desta safra, apresentou duas outras, com maior volume de produção (1943 e 1944), uma pequena (1945) e uma extraordinária (1946), chegando a se colocar logo abaixo do Bourbon amarelo, com pouco mais do que o Bourbon.

Pela média da produção no período todo (1935-1946), a variedade mais produtiva foi o Bourbon amarelo, seguida muito de perto pelo Bourbon. Em terceiro lugar colocou-se o Sumatra, com uma diferença bem apreciável para o Bourbon. Finalmente, quase que em igualdade de condições, ficaram as três últimas variedades, na seguinte ordem: Nacional, Amarelo de Botucatu e Maragogipe. 


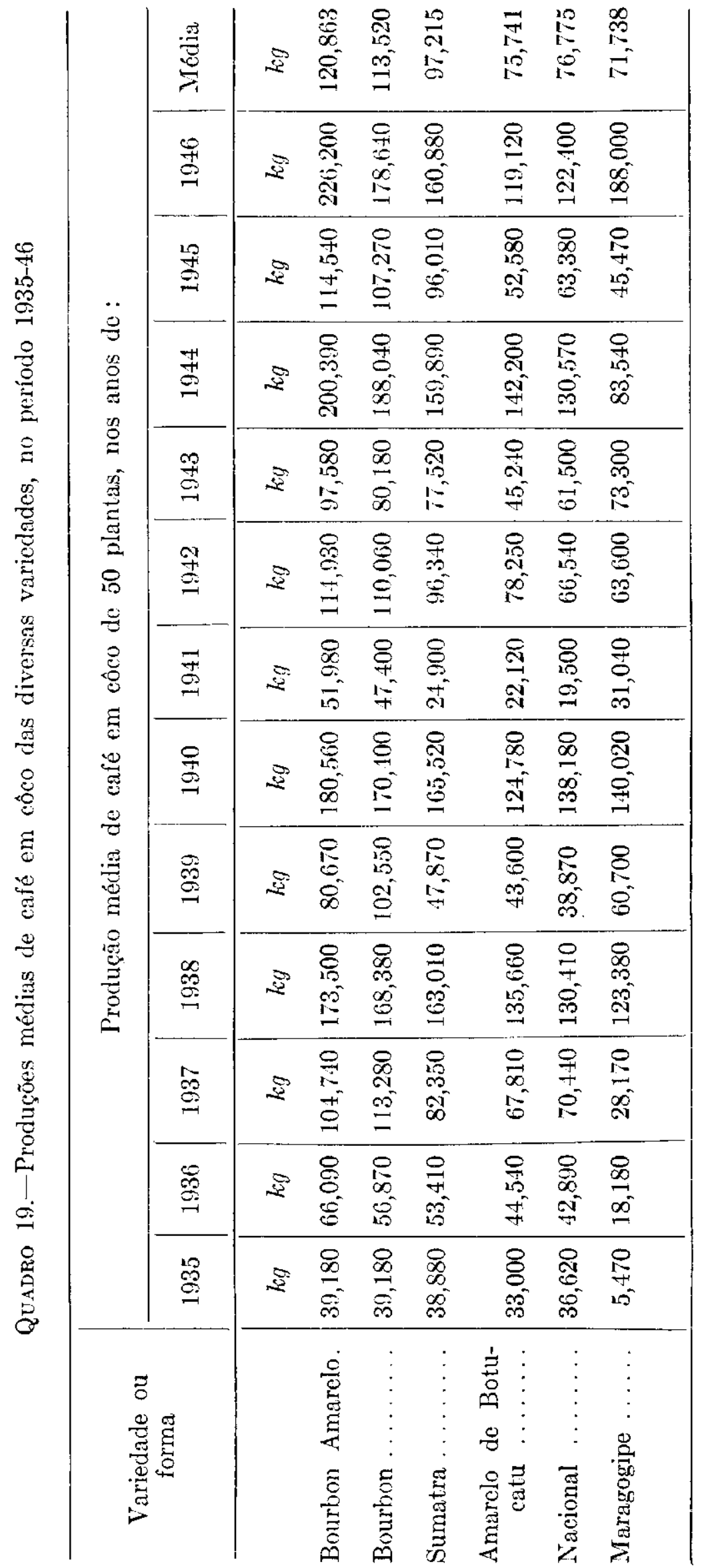


Se dividirmos o período de 12 anos (1935-1946) em quatriênios e obtivermos as médias de produção, vamos ter os dados do quadro 20 .

Quadro 20.--Produções médias de café em côco, por quatriênios, para as seis variedades estudadas

\begin{tabular}{|c|c|c|c|}
\hline \multirow{2}{*}{ Variedade ou forma } & \multicolumn{3}{|c|}{$\begin{array}{l}\text { Produção média de café em côco, por } \\
50 \text { plantas, por quatriênios }\end{array}$} \\
\hline & 1935-1938 & $1939-1942$ & $1943-1946$ \\
\hline & $k g$ & $\mathrm{~kg}$ & $k g$ \\
\hline Bourbon amarelo & 95,87 & 107,03 & 159,68 \\
\hline Bourbon ......... & 94,45 & 107,60 & 138,53 \\
\hline Sumatra .......... & 84,42 & 83,66 & 123,36 \\
\hline Amarelo de Botucatu $\ldots \ldots \ldots \ldots \ldots \ldots$ & 70,27 & 67,19 & 89,78 \\
\hline Nacional $\ldots \ldots \ldots \ldots \ldots \ldots$ & 70,07 & 65,77 & 94,46 \\
\hline Maragogipe. . . . . . . . . . . . . . . . . & 43,82 & 73,84 & 97,57 \\
\hline
\end{tabular}

Os resultados do primeiro quatriênio já foram estudados em trabalho anterior (1). Por essa ocasião, a classificação das variedades foi a seguinte :

1- Bourbon amarelo
Bourbon
2--Sumatra
3-Amarelo de Botucatu
Nacional
4- Maragogipe

No segundo quatriênio (1939-1942), os dois Bourbons ocuparam o primeiro lugar, com produção quase idêntica ; o Sumatra manteve a segunda colocação. $\mathrm{O}$ fato notável verificado foi ter o Maragogipe superado o Amarelo de Botucatu e o Nacional, apesar de a diferença entre os três ser diminuta. A classificação das variedades foi a seguinte :

$$
\begin{aligned}
& \text { 1- Bourbon } \\
& \text { Bourbon amarelo } \\
& \text { 2- Sumatra } \\
& \text { 3- Maragogipe } \\
& \text { Amarelo de Botucatu } \\
& \text { Nacional }
\end{aligned}
$$

No último quatriênio (1943-1946) começa o Bourbon amarelo a se distanciar do Bourbon ; o Sumatra é o terceiro colocado ; o Maragogipe mantém-se superior ao Nacional e ao Amarelo de Botucatu, apesar de a diferença de produção entre essas três variedades não ser grande. A classificação foi a seguinte : 
1-Bourbon amarelo

2-Bourbon

3-Sumatra

4-Maragogipe

Nacional

Amarelo de Botucatu

Destacam-se alguns fatos muito importantes para o prosseguimento de nossos trabalhos com o cafeeiro, principalmente no setor relacionado com o seu melhoramento.

a) O Bourbon amarelo é muito produtivo e está produzindo mais do o Bourbon.

b) O Bourbon é também grandemente produtivo.

c) O Sumatra, apesar de manter sempre a sua posição, é inferior aos dois Bourbons.

d) O Maragogipe aumentou sensìvelmente sua produção, mas não pode ainda confrontar-se com as três variedades anteriores; na média geral, é um pouco inferior ao Nacional e ao Amarelo de Botucatu.

e) O Nacional e o Amarelo de Botucatu apresentaram produção muito baixa.

\section{4-ANÄLISE ESTATÍSTICA DA PRODUÇĀO}

A análise estatística do ensaio, realizada pelo prof. W. L. Stevens, a ser publicada neste mesmo volume de Bragantia, demonstrou o seguinte:

a) não há diferença estatística entre a produção do Bourbon amarelo e do Bourbon;

b) não há diferença estatística entre a produção do Nacional, Amarelo de Botucatu e Maragogipe ;

c) as colheitas das variedades Bourbon amarelo, Sumatra e Maragogipe estão crescendo ;

d) as colheitas do Bourbon e do Nacional não demonstram tendência positiva ou negativa de crescimento;

e) as colheitas do Amarelo de Botucatu apresentam uma tendência para a diminuição.

De acôrdo com êsse estudo, poderemos classificar as variedades em três grupos, estatìsticamente diferentes quanto à produção. Assim:

1-Bourbon amarelo

Bourbon
2-Sumatra

3-Nacional

Amarelo de Botucatu

Maragogipe 


\section{SUMMARY}

An experiment was started in 1931 for the purpose of making a comparative study of the productivity of following varieties of Coffea arabica L. :

Nacional (Coffea arabica L. var. typica Cramer)

Amarelo de Botucatu (Coffea arabica $\mathbf{L}$. var. typica Cramer forma xanthocarpa (Caminhoá) Krug)

Bourbon (Coffea arabica L. var. bourbon (B. Rodr.) Choussy)

Bourbon amarelo (Coffea arabica L. var. bourbon (B. Rodr.) Choussy forma xanthocarpa Krug)

Sumatra (Coffea arabica I. var. typica Cramer)

Maragogipe (Coffea arabica L. var. maragogipe Hort. ex Froehner)

The results obtained from this experiment for the period 1935-1938 have been the subject of a previous publication. The present paper concerns results obtained from the same experiment for the period 1939-1946.

The data obtained have been analysed by varieties and years in relation to: date of ripening of coffee berries, average size of coffee beans and total production. The results of this analysis showed that there were definite annual variations in production by varieties.

With respect to ripening of fruits (cherries) on the varieties tested, it was found that the Amarelo de Botucatu variety had the earliest date of ripening in every year. 'The Nacional and Sumatra varieties varied by years but they were always later than the Amarelo de Botucatu in date of maturity of the cherries. The fruits of Bourbon and Boubon Amarelo were slightly later than all of of the above mentioned varieties and the Maragogipe matured fruit later than all other varieties studied.

The data on the average size of coffee beans showed that the Maragogipe variety produced the largest bean. The Bourbon Amarelo and Bourbon produced beans of the smallest size. 'The Nacional, Sumatra and Amarelo do Botucatu produced beans that were intermediate in size between the Maragogipe and Bourbon.

The analysis of production showed that for each year for the first four years (19351938 ) there was a definite yearly increase in production for each variety tested. The data obtained for subsequent years (1939-1946) show that, for all except the Maragogipe variety, cach year with a high yield was followed by a year with lower coffee production (see figure 1).

On the basis of the total production for the entire period studied (1935-1946) it was found that Bourbon Amarelo variety was the most productive followed closely by the variety Bourbon. The Sumatra variety was intermediate in total production and appreciably less than the Bourbon types. The lowest yielding varieties in this experiment were Nacional, Amarelo de Botucatu and Maragogipe.

The production data have also been studied by four year periods and as a result certain interesting minor variations in relation to varieties have been noted.

$\Lambda$ more detailed statistical analysis of the production data from this experiment has been carried out by Prof. W. L. Stevens (see following article in this issue). He has showed that the coffee varieties studied can be placed in three statistically different classes. The varieties, by classes, according to their decreasing capacity of production, are as follows: a ) Bourbon Amarelo and Bourbon; b) Sumatra ; c) Nacional, Amarelo de Botucatu and Maragogipe.

\section{IITERATURA CITADA}

1. Mendes, J. E. Teixeira Ensaio de variedades de cafeciros. Bol. Tée. Inst. Agr. do Est. S. Paulo (Campinas) 65 : 1-36. 1939.

2. Krug, C. A. O cálculo da peneira média na seleção do cafeeiro. Revista do Instituto do Café do Est. de S. Paulo 15 : 123-127. 1940. 